\title{
FLORAL BIOLOGY AND POLLINATION ECOLOGY OF DESMOS CHINENSIS (ANNONACEAE): ASSESSING THE EFFICACY OF FLORAL SYNCHRONY FOR PROMOTING XENOGAMY
}

\author{
Chun-Chiu Pang* and Richard M. K. Saunders ${ }^{1, *}$ \\ *School of Biological Sciences, The University of Hong Kong, Pokfulam Road, Hong Kong, China \\ Editor: Elena M. Kramer
}

\begin{abstract}
Premise of research. Early-divergent angiosperms typically possess hermaphroditic flowers but often lack any biochemically mediated self-incompatibility mechanism. Although outcrossing is generally promoted in these taxa by protogyny, which is effective for precluding autogamy (self-fertilization within a flower), other mechanisms are necessary to prevent geitonogamy (self-pollination between different flowers within an individual). In this article we investigate the occurrence and efficacy of inter- and intraindividual floral synchrony for preventing geitonogamy in the early-divergent angiosperm Desmos chinensis (Annonaceae) within the context of the overall floral biology and pollination ecology of the species.
\end{abstract}

Methodology. We assess the floral phenology (at the flower, individual plant, and population levels), floral scent chemistry, pollination ecology, and breeding system of $D$. chinensis.

Pivotal results. Desmos chinensis is pollinated by small Amystrops beetles (Nitidulidae) that are attracted by floral scent. Although the flowers are hermaphroditic and self-compatible, population genetic analysis indicates that the species is likely to be predominantly xenogamous (outcrossing): most of the genetic diversity occurs within populations, with evidence of extensive gene flow. The flowers are protogynous, with anthesis lasting ca. $27 \mathrm{~h}$ and with a 6-h nonsexual interim phase separating the functional pistillate and staminate phases. Although protogyny is an effective mechanism to prevent autogamy, it cannot prevent geitonogamy.

Conclusions. We demonstrate the existence of inter- and intraindividual floral synchrony in D. chinensis, in which pistillate- and staminate-phase flowers rarely coexist within an individual, thereby largely precluding the possibility of geitonogamy. We suggest that inter- and intraindividual floral synchrony may be much more common than previous studies suggest. Since the phenomenon is known from several phylogenetically disparate lineages in the family and has possibly evolved independently, it may endow a significant selective advantage for promoting xenogamy.

Keywords: Annonaceae, breeding system, floral scent, floral synchrony, pollination, xenogamy.

\section{Introduction}

Biochemically mediated self-incompatibility mechanisms are widespread in angiosperms, effectively suppressing inbreeding depression in populations and hence increasing reproductive fitness. Self-incompatibility has been implicated as one of the key evolutionary innovations that enabled the rapid diversification of angiosperms during the Cretaceous (Whitehouse 1950; Zavada and Taylor 1986; Igic et al. 2008) and is likely to have evolved independently in different lineages (Charlesworth et al. 2005) since different genetic control mechanisms exist, expressed in either the gametophytic or the sporophytic generations (Allen and Hiscock 2008). Self-incompatibility has been shown to be lacking in many early-divergent angiosperms,

\footnotetext{
${ }^{1}$ Author for correspondence; e-mail: saunders@hku.hk.
}

Manuscript received November 2014; revised manuscript received December 2014; electronically published February 25, 2015. however, including the Amborellaceae and some Nymphaeales and Magnoliales, such as the Annonaceae and Magnoliaceae (Bernhardt and Thien 1987; Dieringer and Espinosa 1994; Allen and Hiscock 2008; Pang and Saunders 2014). It has been hypothesized that the deleterious genetic consequences arising from the absence of self-incompatibility in these early-divergent lineages may be offset by selective advantages arising from the ability to reproduce under unfavorable conditions, such as isolated populations where there are constraints on the number of genetically distinct individuals and periods where pollinator availability is limited (Barrett and Eckert 1990; Lloyd 1992; Goodwillie et al. 2005; Pang and Saunders 2014). Selfcompatible early-divergent angiosperms have nevertheless been shown to exhibit a diversity of alternative mechanisms that promote outcrossing (xenogamy) by reducing self-fertilization and biparental inbreeding, including intrafloral dichogamy (the temporal separation of pistillate and staminate function in hermaphroditic flowers), herkogamy (the spatial separation of pollen presentation and receipt in hermaphroditic flowers), floral 
synchrony, and the evolution of structurally or functionally unisexual flowers (Endress 2010; Pang and Saunders 2014). Achieving high levels of xenogamy is clearly of considerable importance, even in plants that are self-compatible.

This study evaluates the effectiveness of inter- and intraindividual floral synchrony for promoting xenogamy in Desmos chinensis, a representative of the early-divergent angiosperm family Annonaceae. As with many Annonaceae species, D. chinensis flowers are hermaphroditic and protogynous, with anthesis extending over a 2 -d period and with the pistillate phase occurring $1 \mathrm{~d}$ ahead of the staminate phase. Inter- and intraindividual floral synchrony involves two distinct phenological cohorts within the population so that all the flowers borne concurrently on an individual are synchronized in the same sexual phase, ensuring that the transfer of pollen between flowers can occur only between different individuals. This type of floral synchrony has been reported in several earlydivergent angiosperm families, including the Eupomatiaceae (Endress 1984), Canellaceae (Wilson 1982), and Annonaceae. The Annonaceae is perhaps the best-studied family in terms of this mechanism, with reports of floral synchrony in several disparate lineages, viz., subfam. Malmeoideae tribe Maasieae (Maasia; Rogstad 1994, as Polyalthia) and subfam. Annonoideae tribes Annoneae (Annona; Murray and Johnson 1987, as Rollinia; Lora et al. 2011), Guatterieae (Guatteria; Webber 2002), and Uvarieae (the Dasymaschalon-Desmos-Friesodielsia clade; Pang and Saunders 2014; X. Guo, personal communication). The occurrence of this type of floral synchrony in such disparate evolutionary lineages suggests that it is functionally very significant.

Inter- and intraindividual floral synchrony have not received much attention, however, probably because they are difficult to detect in the field: in order to reveal floral synchrony, it is necessary to monitor floral phenological changes in multiple individuals over several consecutive days, an undertaking that is beyond the scope of many studies. We suggest that the phenomenon is likely to be much more common in early-divergent angiosperms than existing reports suggest. Despite evidence for the independent evolution of floral synchrony in disparate lineages in the Annonaceae, the genetic consequences of the mechanism have never been assessed. This study describes the floral biology and pollination ecology of $D$. chinensis, including observations of floral phenology, floral thermogenesis, floral scent chemistry, and assessments of effective pollinators and plant breeding system. Floral thermogenesis and scent chemistry analysis can provide convincing evidence to support the pollination ecology of $D$. chinensis, as they are often strongly associated with pollinator behavior. In particular, we use genetic diversity and gene flow within and between populations to evaluate the efficacy of floral synchrony for promoting outcrossing.

\section{Material and Methods}

\section{Study Site}

Field observations were conducted in Hong Kong, China, where Desmos chinensis is a common and dominant understory species, particularly in natural lowland forests and artificially managed feng shui woods near villages. Three popu- lations were selected for the study, viz., Lung Fu Shan Country Park (lat. $22^{\circ} 16^{\prime} \mathrm{N}$, long. $114^{\circ} 07-08^{\prime} \mathrm{E}$ ), Pokfulam Country Park (lat. $22^{\circ} 15-16^{\prime} \mathrm{N}$, long. $114^{\circ} 07-09^{\prime} \mathrm{E}$ ), and Ho Sheung Heung feng shui wood (lat. $22^{\circ} 30^{\prime} 32-47^{\prime \prime} \mathrm{N}$, long. $114^{\circ} 06^{\prime} 20$ $\left.28^{\prime \prime} \mathrm{E}\right)$. All three sites support healthy populations of $D$. chinensis with abundant pollinators. Voucher herbarium specimens have been deposited in the University of Hong Kong herbarium (C.C. Pang PCC06, Aug. 22, 2011; C.C. Pang PCC10, Sept. 1, 2011).

\section{Floral Phenology}

Phenological studies were conducted over four consecutive flowering seasons (2008-2011) in order to identify the timing and duration of floral sexual stages and to evaluate possible synchrony in anthesis at individual and population levels. A total of 200 flower buds from 20 individuals were tagged and monitored every day until sexual maturity. Observations were subsequently taken at 2-h intervals until the end of the staminate phase. The onset and duration of stigmatic receptivity, presence or absence of stigmatic exudate, and color changes in the stigmas were recorded throughout the pistillate phase. Stigmatic receptivity was determined by immersing the stigmas in 3\% hydrogen peroxide $\left(\mathrm{H}_{2} \mathrm{O}_{2}\right)$ solution and observing bubble formation (Dafni 1992), which is the result of peroxidase enzyme activity (Galen and Plowright 1987). The presence of stigmatic exudate was observed to be correlated with stigmatic receptivity and was accordingly used as supporting evidence for determining the onset of the pistillate phase (Dafni 1992). The staminate phase was recognized by anther dehiscence, with the timing and duration of pollen availability and associated color changes recorded throughout the staminate phase. The presence of a sexually nonfunctional interim phase between the end of the pistillate phase and the onset of the staminate phase was also assessed.

Inter- and intraindividual floral synchrony were investigated by surveying 10 individual plants over 10 consecutive days in the Ho Sheung Heung population in the summer of 2008 (Pang and Saunders 2014). The simultaneous occurrence of pistillate-, interim-, and staminate-phase flowers within and between individual plants was determined.

\section{Assessment of Floral Visitors}

Observations of floral visitors were conducted by surveying a total of 100 flowers from 16 individual plants in both Lung Fu Shan and Ho Sheung Heung populations in 2010 and 2011. Flowers were observed throughout anthesis at 2-h intervals to record the arrival and departure patterns of the floral visitors. The following criteria were used to determine whether floral visitors were effective pollinators: (1) relative visitation rates; (2) the coincidence of visits and the duration of pistillate or staminate phases in the flowers; (3) the attachment of D. chinensis pollen grains to the floral visitors, determined using LM and/or SEM; and (4) evidence of movement of floral visitors between flowers of different anthetic phases.

A sample of each species of floral visitor was immobilized in an Eppendorf tube containing absorptive paper soaked with chloroform. After checking for the presence of attached pollen grains, the insects were stored in $70 \%$ alcohol for further as- 
sessment and/or identification. Floral visitors were identified to genus level by entomologists from the Natural History Museum in London.

\section{Floral Thermogenesis and Floral Scent Analysis}

Temperature measurements inside the floral chambers of 10 D. chinensis flowers were recorded using a digital temperature datalogger (Testo 176-T4, Germany), with type-K thermocouples that have an accuracy of $\pm 0.3^{\circ} \mathrm{C}$. Measurements were taken at 15 -min intervals from the start of the pistillate phase until the end of the staminate phase. Ambient temperatures outside the floral chamber were collected simultaneously using an identical cross-calibrated temperature sensor.

Floral scents were collected from different anthetic phases using a solid-phase microextraction (SPME) fiber with a $65-\mu \mathrm{m}$ divinylbenzene/polydimethylsiloxane coating mounted on a manual sampling device (Supelco, Bellefonte, PA). Flowers were placed in previously unused polypropylene bags that were sealed to limit air movement (Azuma et al. 2001). A purified SPME fiber was inserted into the bag and exposed for $2 \mathrm{~h}$ to enable adsorption of volatile compounds; the fibers were then transferred to the School of Biological Sciences at the University of Hong Kong for gas chromatography-mass spectrometry (GCMS) analysis. An Agilent 6890N gas chromatograph (Agilent Technologies, Palo Alto, CA) was used, coupled with an Agilent 5973 mass selective detector with a $30 \times 0.255-\mathrm{mm}$ i.d. DB-WAX capillary column and a $0.25-\mu \mathrm{m}$ film ( $\mathrm{J}$ and W Scientific, Folsom, CA). Helium was selected as the carrier gas, with an injection temperature of $250^{\circ} \mathrm{C}$ for $1 \mathrm{~min}$ to allow vaporization of volatile compounds. The oven was maintained at $50^{\circ} \mathrm{C}$ for the first $5 \mathrm{~min}$, raised by $5^{\circ} \mathrm{C} \min ^{-1}$ to $230^{\circ} \mathrm{C}$, and then maintained at $230^{\circ} \mathrm{C}$ for $20 \mathrm{~min}$. Electron ionization mass spectrometry was used with an acquisition range of 30$650 \mathrm{~m} / \mathrm{z}$. The volatile compounds were identified by comparing their mass spectra against the NIST 02 MS library bundle (National Institute of Standards and Technology, Gaithersburg, MD). Compounds with estimated identity likelihoods below $80 \%$ were considered unknown (Ratnayake et al. 2007; Pang et al. 2013). Kovats index values were calculated against $n$-alkane standards to confirm compound identity of chemicals with retention times longer than 5 min (Kovats 1965).

\section{Plant Breeding System}

The breeding system of $D$. chinensis was assessed using two approaches: field-based controlled pollination experiments and lab-based inter-simple sequence repeat (ISSR) analysis. The controlled pollination experiments were conducted during the peak flowering season when the maximum number of flowers was available. All flowers were covered with durable fine-mesh chiffon bags before they reached sexual maturity to ensure exclusion of floral visitors (Dafni 1992). The range of possible controlled pollination experiments was limited by the presence of the pollination chamber and the large number of stamens, which restrict the possibility of floral manipulations including emasculation: previous experience has shown that the removal of petals and/or stamens typically results in abscission of the entire flower. A total of four controlled pollination treatments were undertaken (adapted from Dafni 1992), using toothpicks to artificially pollinate flowers: (1) the control, in which flowers were not bagged and were left to freely pollinate; $(2)$ a test for geitonogamy, in which flowers were bagged prior to anthesis and then artificially pollinated using pollen from another flower of the same individual that had previously been bagged; (3) a test for xenogamy, in which flowers were bagged prior to anthesis and then pollinated with pollen from a different individual (at least $10 \mathrm{~m}$ distant); and (4) a test for autogamy, in which flowers were bagged prior to anthesis and left unpollinated. If protogyny is demonstrated, treatment 4 can also be regarded as a test for agamospermy.

Bags were not removed until fruit maturity to prevent ripening monocarps from being taken by birds. The number of developing fruits in each treatment was counted at 2-wk intervals until fruit maturity. Failure of fruit set was indicated by the abscission of the entire flower. Self-incompatibility was estimated by calculating the index of self-incompatibility (ISI), in which the number of flowers that set fruit after self-pollination is divided by the number resulting from cross-pollination (e.g., Bawa 1974; Zapata and Arroyo 1978; Stephenson et al. 2000; Igic and Kohn 2006). ISI values were used to define the following categories: $0=$ entirely self-incompatible, $0-0.2=$ mostly self-incompatible, $0.2-1=$ incompletely self-compatible, and 1 = entirely self-compatible.

For the ISSR analysis, young leaf samples from designated individuals were collected and dried using silica gel. Leaf samples (20 mg/individual) were ground over liquid nitrogen using an autoclaved mortar and pestle, and the total DNA was isolated using a DNeasy plant kit (Qiagen, Hilden, Germany) and stored at $-20^{\circ} \mathrm{C}$. A total of 100 primers, $15-23$ nucleotides in length (USB ISSR primer, oligonucleotide set 100/9; Biotechnology Laboratory, University of British Columbia, Vancouver), were screened and eight primers used for single-primer PCR amplifications. PCR amplifications were performed in a GeneAmp PCR system 2700 (Applied Biosystems, Carlsbad, $\mathrm{CA})$, after which the products were stored at $4^{\circ} \mathrm{C}$.

PCR products were loaded onto $1.8 \%$ agarose gels in $\times 1$ TAE buffer with SYBR Safe DNA gel stain (Invitrogen, Hong Kong, China). The gels were run at constant voltage (Culley and Wolfe 2001), and the gels were visualized under ultraviolet light using a UVP gel documentation system. Fragment sizes were estimated based on a 100-bp DNA ladder (Fermentas, Hong Kong, China), and their sizes were used to assign loci for each primer. Bands were scored as diallelic for each assigned locus, and POPGENE version 1.32 (Yeh et al. 1997) was used to analyze the data, assuming that populations were in HardyWeinberg equilibrium at all loci.

\section{Results}

\section{Floral Phenology}

Seven different stages of floral development are apparent in Desmos chinensis as follows:

Stage I (fig. 1A): early bud (5-6 d). The flower buds are green and orientated more or less horizontally. The buds are initially completely enclosed by the three sepals but subsequently begin to separate, exposing the outer petals, after 2 or $3 \mathrm{~d}$; the outer petals remain closed, and hence the inner petals are not visible. 
Stage II (fig. 1B): petal separation $(2-3 d)$. The flower buds gradually become pendent as their weight increases. The outer petals enlarge slightly and separate, exposing the inner petals. The base of each inner petal is constricted and slightly curved inward to form the floral chamber, which becomes fully developed in the later stages. Both whorls of petals remain green.

Stage III (fig. 1C): petal elongation (5-6 d). The petals remain green, and the buds remain pendent. Both petal whorls elongate, although growth of the outer whorl exceeds that of
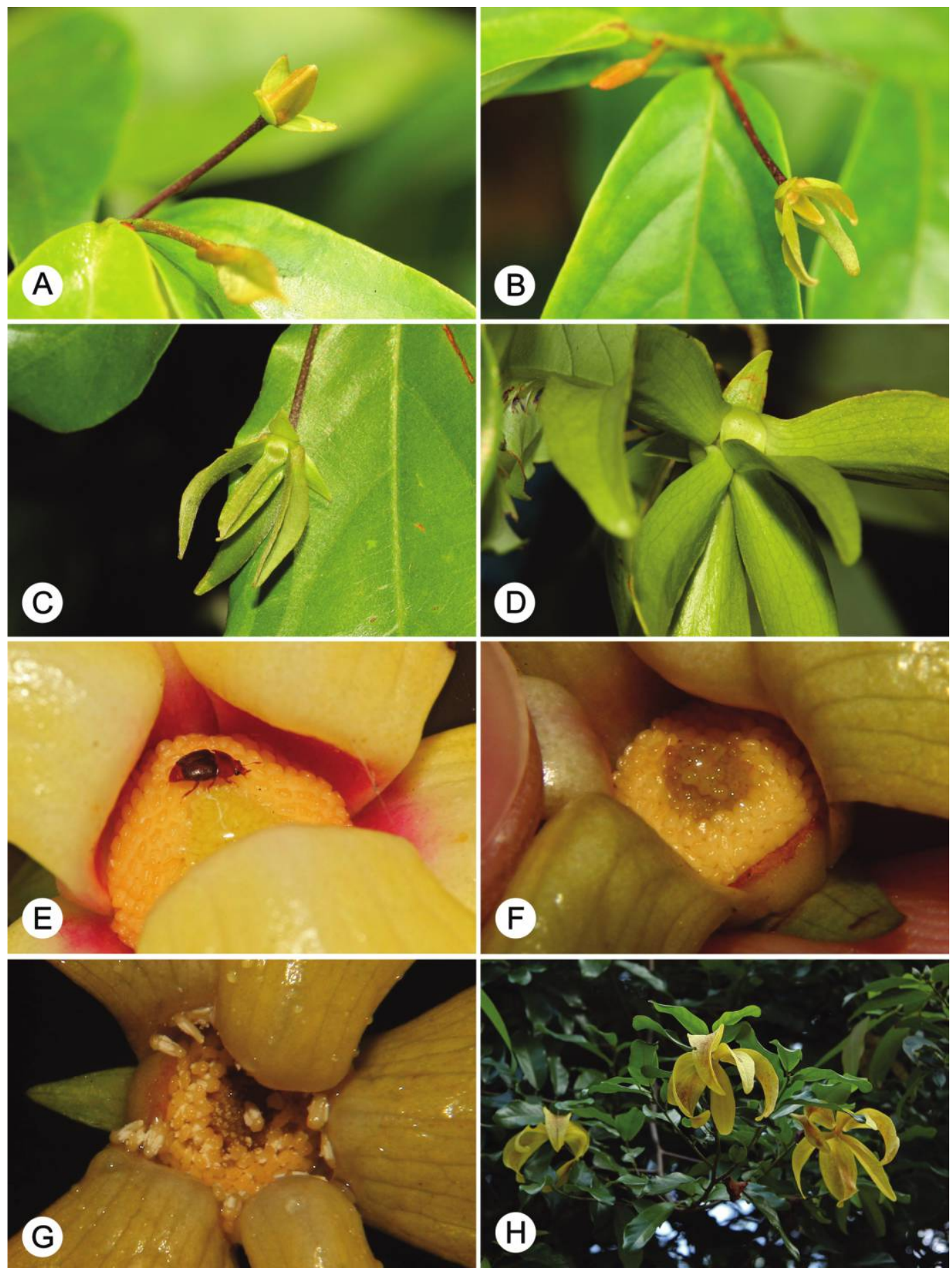

Fig. 1 Flower-level phenological changes in Desmos chinensis. A, Stage I: early bud; $B$, stage II: petal separation; $C$, stage III: petal elongation; $D$, stage IV: floral chamber formation, showing basally constricted petals; $E$, stage V: pistillate phase, showing an Amystrops beetle inside the opened pollination chamber; F, stage VI: interim phase, with the inner petals artificially separated; G, stage VII: staminate phase, with the inner petals artificially separated, showing dehiscent stamens; $H$, mature pistillate-phase flowers. 
the inner whorl. The basal constriction of the inner petals is obvious, although this is not evident in the outer petals.

Stage IV (fig. 1D): floral chamber formation (ca. $10 \mathrm{~d}$ ). Both petal whorls continue to enlarge, and the bud reaches its maximum size toward the end of this stage. The base of the outer petals becomes constricted and inwardly curved, contributing to the formation of the floral chamber. The chamber has four apertures that allow floral visitors to access the reproductive organs of the flower: three of the apertures are located between the basal margins of contiguous inner petals and are loosely occluded by the basal constrictions of the three outer petals, and the other aperture is located at the top of the basal constriction of the inner petals, directly above the gynoecium. The petals begin to turn pale yellow toward the end of this stage.

Stage V (fig. 1E): pistillate phase (ca. 18 b). The flowers remain pendent, and pigmentation of the petals intensifies to bright yellow, with the basal parts of both petal whorls turning red near the reproductive organs. The flowers emit a sweet odor, which is particularly intense in the morning (0600-0800 hours). The onset of stigmatic receptivity in the early morning (ca. 0400 hours) continues until late evening of the same day (ca. 2200 hours; fig. 2); this is associated with the formation of stigmatic exudate ( $\mathrm{a}$ in fig. 2 ) and a color change in the stigmas, which turn greenish-yellow. The staminal connectives also change from green to yellow, although the stamens remain tightly packed and the anthers do not dehisce. Beetle pollinators were observed arriving at the flowers and entering the pollination chamber at the beginning of this phase (b in fig. 2).

Stage VI (fig. $1 \mathrm{~F})$ : interim phase (ca. 6 b). This stage lasts from 2200 to 0400 hours the next day (fig. 2). Stigmatic receptivity diminishes, and the stigmas become dry (c in fig. 2) and turn olive-yellow. The floral scent also diminishes, with almost no odor apparent toward the end of the interim phase. The orientation and color of petals remains unchanged from the pistillate phase.

Stage VII (fig. 1G): staminate phase (ca. 3 b). This stage lasts from 0400 to 0700 hours (fig. 2). The flowers remain pendent, and the thecae dehisce as the stamens begin to abscise (d in fig. 2), with the stamens typically remaining suspended from the receptacle by the extended spiral secondary wall thickenings of the tracheary elements. The stigmas also abscise from the ovaries, and the petals fall from the flower one by one (e in fig. 2), encouraging the departure of pollinators ( $\mathrm{f}$ in fig. 2).

The anthetic period of the flower therefore lasts for ca. $27 \mathrm{~h}$. The assessment of flowering patterns at the population level reveals that the timing of sexual maturation of flowers within an individual plant is synchronized over the anthetic period. A cohort of flower buds on each individual enters the pistillate phase concurrently at about 0400 hours on day 1 ; these flowers subsequently progress to the staminate phase on day 2 , during which time there are no other flowers on the same individual entering the pistillate phase (table 1). Another cohort of mature flowers develops in the morning of day 3 , in which the flowers entering the pistillate phase are not (or are very unlikely to be) pollinated within the same individual, as staminatephase flowers are absent that morning. The cycle continues in a synchronized manner, with a new cohort of mature flowers occurring every $48 \mathrm{~h}$ in each plant.

\section{Assessment of Floral Visitors}

The insect most commonly observed visiting $D$. chinensis flowers was a small beetle (ca. $2 \mathrm{~mm}$ long, abdomen ca. $1.3 \mathrm{~mm}$ wide) belonging to the genus Amystrops (Nitidulidae; fig. $3 \mathrm{~A}$, $3 B$ ). A total of 37 Amystrops individuals were observed from 19 of the 100 flowers surveyed. The average number of beetles recorded in these 19 flowers was 1.95 ( $\mathrm{SD}=1.13$ ), and the maximum number of beetles found in a single pollination chamber was five. The majority of Amystrops beetles were observed arriving and entering the floral chambers of pistillatephase flowers between 0600 and 0800 hours ( $\mathrm{a}$ in fig. 2), where they remained until the end of the staminate phase, finally departing as the petals abscise. Pollen grains were observed attached to the abdomen, thorax, and legs of the beetles (fig. 3C). Only two individuals of an unknown species of curculionid beetle were observed visiting the flowers in the entire study period; this species was accordingly not considered an effective pollinator.

The petals provided a landing platform for the beetles before they entered the floral chamber via the apertures between the inner petals. Although it was difficult to determine the activities of the pollinators inside the floral chamber without opening the floral chamber and disturbing them, they appeared to make contact with the stigmas during the pistillate phase of the flowers.

\section{Floral Thermogenesis and Floral Scent Analysis}

Temperatures within the floral chamber were not significantly higher than ambient levels, irrespective of phenological stage, and hence there is no evidence for floral thermogenesis in D. chinensis. The flowers emit a strong fragrance from the

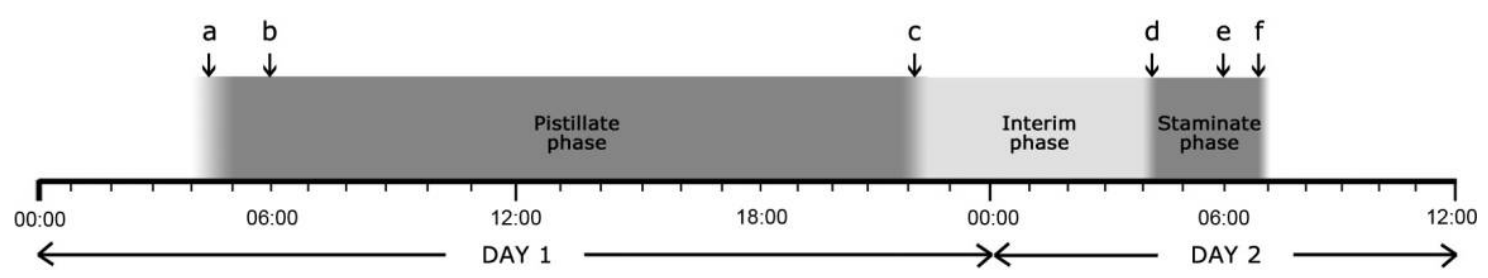

Fig. 2 Timing of phenological events of flowers of Desmos chinensis during sexually functional phases. a $=$ start of stigma exudation and scent emission, $b=$ arrival of pollinators, $c=$ drying of exudate and lowering of scent emission, $d=$ anther dehiscence and release of pollen grains, $\mathrm{e}=$ abscission of petals, $\mathrm{f}=$ departure of pollinators. 
Table 1

Number of Pistillate-Phase and Staminate-Phase Flowers on 10 Individuals of Desmos chinensis, Monitored over 10 Consecutive Days

\begin{tabular}{|c|c|c|c|c|c|c|c|c|c|c|}
\hline \multirow[b]{2}{*}{ Day } & \multicolumn{10}{|c|}{ Individual } \\
\hline & 1 & 2 & 3 & 4 & 5 & 6 & 7 & 8 & 9 & 10 \\
\hline 1 & 0 , ? & 9 , ? & 0 , ? & 3 , ? & 2 , ? & 0 , ? & $0, ?$ & $1, ?$ & 0 , ? & $0, ?$ \\
\hline 2 & 2,0 & 0,9 & 12,0 & 0,3 & 0,2 & 20,0 & 3,0 & 5,1 & 8,0 & 0,0 \\
\hline 3 & 0,2 & 10,0 & 0,12 & 7,0 & 3,0 & 0,20 & 0,3 & $\overline{0,5}$ & 0,8 & 0,0 \\
\hline 4 & 4,0 & 0,10 & 4,0 & 1,7 & 0,3 & 11,0 & 2,0 & 4,0 & 6,0 & 0,0 \\
\hline 5 & 0,4 & 8,0 & 0,4 & $\overline{5,1}$ & 7,0 & 0,11 & 1,2 & 0,4 & 2,6 & 37,0 \\
\hline 6 & 0,0 & 1,8 & 8,0 & $\overline{0,5}$ & 0,7 & 13,0 & $\overline{2,1}$ & 2,0 & $\overline{1,2}$ & 0,37 \\
\hline 7 & 0,0 & $1 \overline{0,1}$ & 0,8 & 2,0 & 3,0 & 0,13 & $\overline{0,2}$ & 0,2 & $\overline{0,1}$ & 15,0 \\
\hline 8 & 0,0 & $\overline{0,10}$ & 15,0 & 0,2 & 0,3 & 9,0 & 1,0 & 1,0 & 8,0 & 0,15 \\
\hline 9 & 0,0 & 5,0 & 2,15 & 1,0 & 4,0 & 0,9 & 0,1 & 0,0 & 0,8 & 7,0 \\
\hline 10 & 0,0 & 0,5 & $\overline{8,2}$ & 0,1 & 0,4 & 9,0 & 2,0 & 0,0 & 3,0 & 0,7 \\
\hline Pistillate-phase flowers & & & & & & & & & & \\
\hline available for geitonogamy & 0 & 11 & 10 & 6 & 0 & 0 & 3 & 5 & 3 & 0 \\
\hline
\end{tabular}

Note. For each individual, values shown are number of pistillate-phase flowers, followed by number of staminate-phase flowers. Co-occurrence of pistillate- and staminate-phase flowers is underlined. Table adapted from Pang and Saunders (2014).

start of the pistillate phase; the scent is most intense in the early morning (ca. 0600 hours), diminishing toward the end of the pistillate phase until the flowers become almost odorless during the nonreceptive interim and staminate phases.

A total of 79 volatile compounds were detected in the floral scents of pistillate-, interim-, and staminate-phase flowers using GCMS (table 2). Of these, nine, five, and eight compounds were unique to the three phases, respectively.

\section{Plant Breeding System}

The controlled pollination experiments were conducted in both Lung Fu Shan and Ho Sheung Heung populations during the peak flowering season in 2009. In total, 96 flowers were used in the four treatments: 36 flowers for the control (treatment 1), 8 flowers for the test for geitonogamy (treatment 2), 32 flowers for the test for xenogamy (treatment 3), and 20 flowers for the test for autogamy (treatment 4). The sample size for the test of geitonogamy was constrained by the limited number of pistillate- and staminate-phase flowers borne concurrently within a single individual.

All flowers in the test for autogamy (treatment 4) withered and abscised within 2-7 wk (fig. 4), and consequently no fruit set was observed. The percentage fruit set $(10 \mathrm{wk}$ after pollination) resulting from the tests for geitonogamy, xenogamy, and the control were $75.0 \%, 81.3 \%$, and $27.8 \%$, respectively (fig. 4). No abscission of flowers occurred within the first 2 wk, irrespective of whether fertilization had occurred. Fruit loss in all
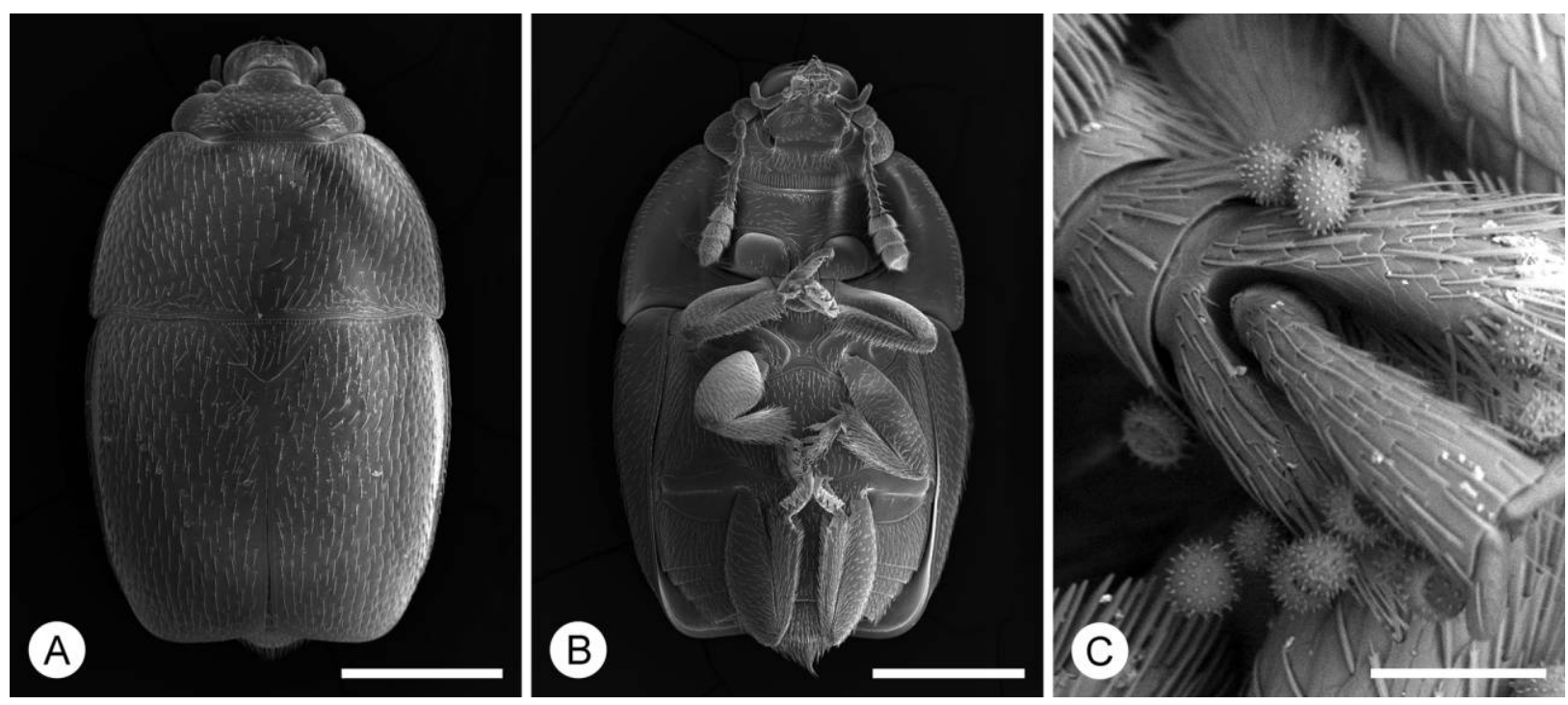

Fig. 3 Amystrops sp. (Coleoptera: Nitidulidae), the effective pollinator of Desmos chinensis. A, Dorsal view. B, Ventral view. C, Pollen grains of $D$. chinensis deposited on the legs and abdomen. Scale bars: $A, B=0.5 \mathrm{~mm} ; C=0.1 \mathrm{~mm}$. 
the treatments gradually decreased 2-9 wk after pollination. All the artificially pollinated flowers were kept bagged after pollination, and therefore loss of developing fruits was presumably due to inbreeding depression and/or failure of fertilization rather than frugivory. The high levels of fruit set following geitonogamy and xenogamy indicate that selfing is possible; the ISI was correspondingly high (0.92).

A total of 78 ISSR loci were scored from eight primers using 24 individuals from the Lung Fu Shan population and 22 individuals from the Pok Fu Lam population. Bands ranged in size from 230 to $2200 \mathrm{bp}$, and the number of amplified ISSR fragments ranged from 5 to 13 bands/primer, with an average of 9.75 . Various parameters describing the population genetic structure were calculated (table 3 ).

\section{Discussion}

\section{Floral Biology and Pollination Ecology}

Desmos chinensis flowers are clearly protogynous, with anthesis extending over $27 \mathrm{~h}$, from 0400 hours with the onset of stigmatic receptivity to 0700 hours the following day when the petals abscise. The pistillate and staminate phases are separated by a 6 -h nonsexual interim phase that effectively precludes autogamous self-pollination.

Beetles belonging to a species in the genus Amystrops (Nitidulidae) were the major floral visitors to $D$. chinensis that entered the floral chamber. This Amystrops species fulfils all the criteria for determining effective pollination: the arrival and departure times of the beetles coincided with the floral reproductive phases, and pollen grains of $D$. chinensis were observed not only attached to the bodies of the beetles (fig. $3 C$ ) but also on beetles collected from pistillate-phase flowers, providing unequivocal evidence of interfloral movement. Nitidulid beetles are commonly reported as pollinators of other Annonaceae species (Silberbauer-Gottsberger et al. 2003; Saunders 2012). Flowers of $D$. chinensis show many characteristics typical of cantharophily, including a partially enclosed pollination chamber with small apertures, pale-colored petals, and hairy ovaries surrounded by tightly packed stamens with extended connectives (van Heusden 1992; Saunders 2012).

The Amystrops beetles are likely to be attracted to the flowers by the strong scent that is emitted at the start of the pistillate phase. GCMS analysis of the floral volatiles indicates that beetle attractants and putative sexual pheromone mimetics are likely to be important components of the fragrance. Several of the compounds identified from the floral scent of $D$. chinensis have previously been reported to be either attractants or sexual pheromones for Coleoptera, including (Z)-3,7-dimethyl-1,3,6-octatriene, R,S-linalool, 3,7-dimethyl2,6-octadien-1-ol, benzaldehyde, heptacosane, octacosane, pentacosane, phenol, tetradecane, tetratriacontane, $\alpha$-caryophyllene, and $\alpha$-cubebene (Jürgens et al. 2000; El-Sayed 2006 and references therein). In addition, phenol-2,4-bis-(1,1 dimethylethyl), 3,7-dimethyldecane, caryophyllene, dodecane, dodecanoic acid, eicosane, heneicosane, and phenylacetaldehyde oxime, which are also identified from the floral scent, have previously been reported to be attractants or sexual pheromones for other insect orders, including Diptera, Homoptera, Hymenoptera, Isoptera, Lepidoptera, Orthoptera, and Trichoptera, and are therefore also potential attractants for Amystrops (references in El-Sayed 2006).

Some of the compounds recorded here from the floral scent of $D$. chinensis have previously been reported as insect repellents, however, including benzaldehyde, d-limonene, and naphthalene (Azuma et al. 2001; Wyatt 2003; El-Sayed 2006). These compounds possibly repel herbivorous insects that would be ineffective pollinators.

\section{Plant Breeding System}

The absence of fruit-set in the test for autogamy (treatment 4) indicates that spontaneous self-pollination does not occur in D. chinensis. This is undoubtedly due to the existence of protogyny, in which a 6-h nonsexual interim phase separates the pistillate and staminate phases (fig. 2). The existence of protogyny furthermore allows treatment 4 to be interpreted as proof that agamospermy does not occur. The absence of autogamy and agamospermy clearly confirms the requirement for pollen transfer between flowers and is consistent with the observations of floral visits by Amystrops beetles.

The difference in levels of fruit-set (fig. 4) resulting from the control (treatment 1 , with $27.8 \%$ fruit-set) and the test for xenogamy (treatment 3 , with $81.3 \%$ fruit-set) indicates that natural fruit-set is likely to be limited by pollen transfer. This is probably due to the restricted availability of pollinators, although this problem may be site dependent, as fruit-set is likely to vary between populations and possibly also between flowering seasons due to fluctuations in pollinator availability (Mayer et al. 2011). Comparisons of ISI values for other species (e.g., Bawa 1974; Zapata and Arroyo 1978; Stephenson et al. 2000; Igic and Kohn 2006) suggest that $D$. chinensis (ISI $=0.92$ ) is likely to be highly self-compatible and that a genetically controlled self-incompatibility mechanism is unlikely to operate.

Desmos chinensis shows a high level of genetic variability within populations (table 3 ) in comparison with other longlived perennial woody species (Hamrick et al. 1992; Ge and Sun 1999) and other reported Annonaceae species, inferred using ISSR markers (Ratnayake et al. 2006; Attanayake 2010) and RAPD markers (Huang et al. 2000; table 4). The fact that ca. $90 \%$ of total genetic diversity $\left(H_{\mathrm{T}}=0.31\right.$; table 3$)$ in $D$. chinensis is due to within-population diversity $\left(H_{\mathrm{S}}=0.28\right.$; table 3) suggests that the two populations have similar levels of genetic diversity due to extensive gene flow; this is confirmed by the high level of gene flow between populations calculated $\left(N_{\mathrm{m}}=5.07\right.$; table 3$)$. The coefficient of genetic differentiation between populations $\left(G_{\mathrm{ST}}\right)$ value of 0.09 (table 3) represents the level of gene differentiation among populations and is indicative of the breeding system; the value for $D$. chinensis is lower than that typical of most selfing species $\left(G_{\mathrm{ST}}=0.523\right)$ and mixed-mating species $\left(G_{\mathrm{ST}}=0.243\right)$ and is closer to that of outcrossing species $\left(G_{\mathrm{ST}}=0.118\right.$; Loveless and Hamrick 1984). This suggests that the genetic diversity within D. chinensis populations is very high but that there is poor differentiation among populations due to outcrossing and frequent gene flow. Hamrick et al. (1992) further suggested that the genetic variability within populations of winddispersed species $\left(G_{\mathrm{ST}}=0.077\right)$ is higher than that of animaldispersed species $\left(G_{\mathrm{ST}}=0.099\right)$. The results for $D$. chinensis are 


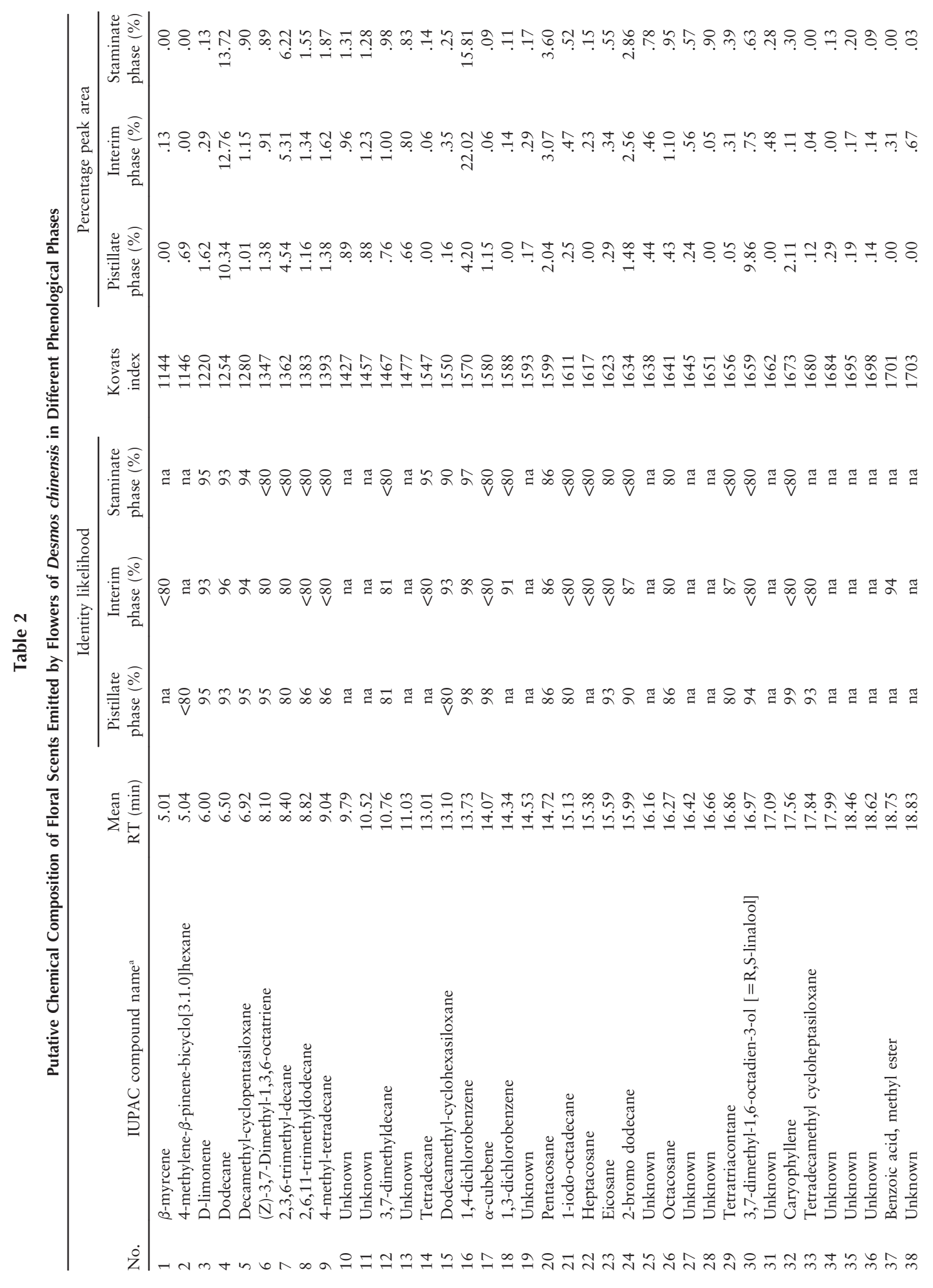




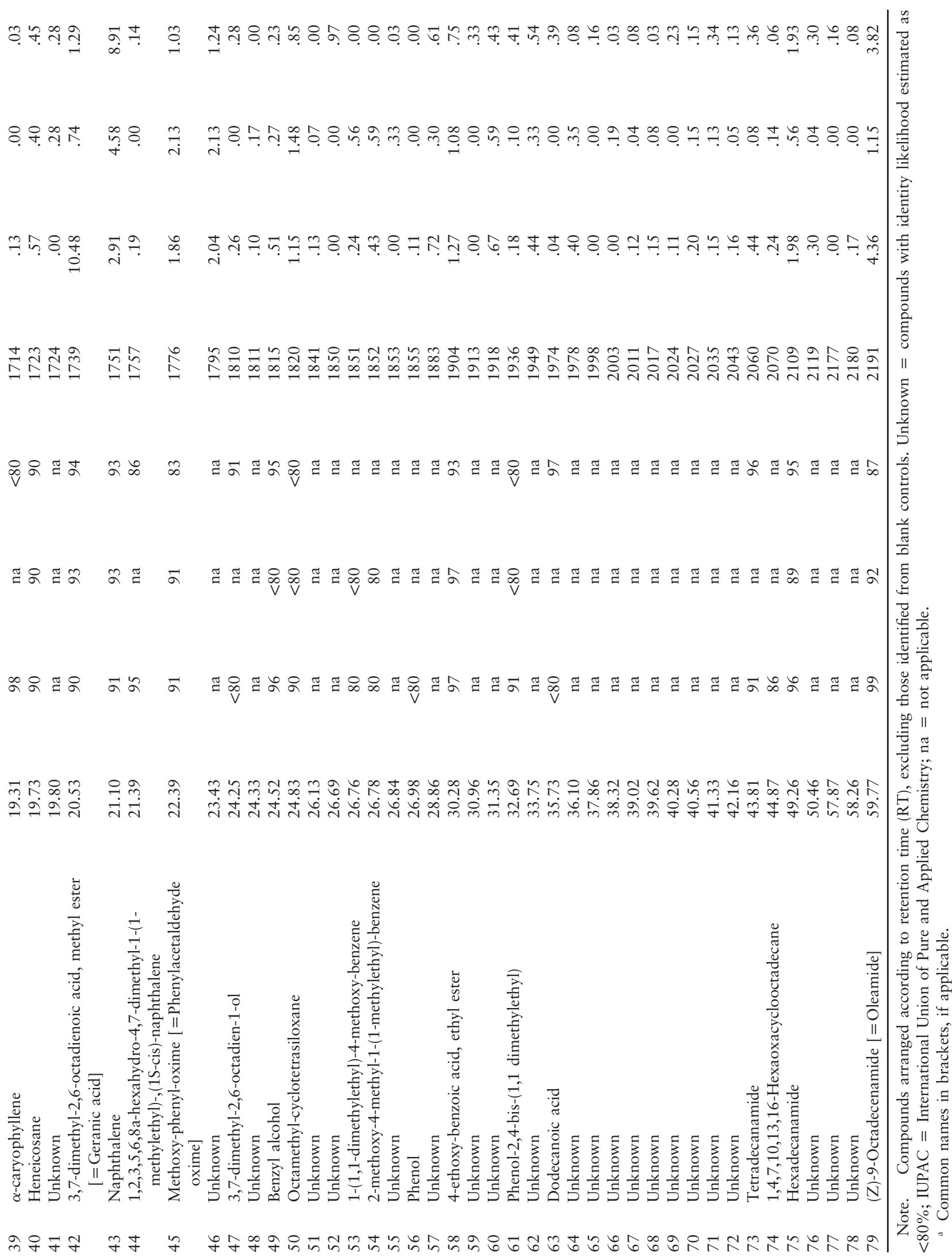




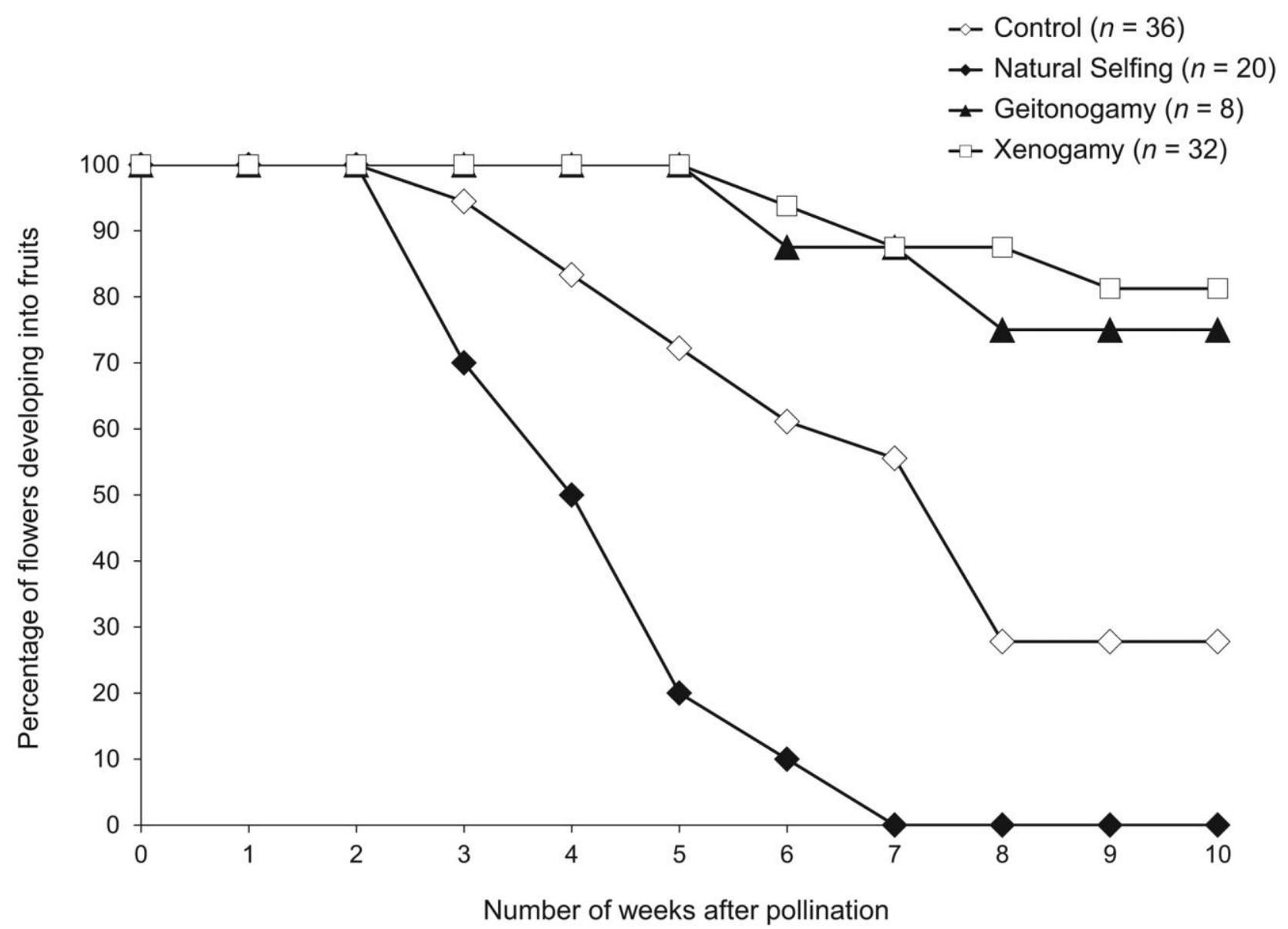

Fig. 4 Percentage of Desmos chinensis fruits developing, following different pollination treatments.

therefore consistent with observations that it is animal dispersed and predominantly outcrosses.

\section{Floral Synchrony}

Anthesis is clearly synchronized within individuals of $D$. chinensis so that almost all flowers borne concurrently are in the same reproductive phase, either pistillate (on the first day of anthesis) or staminate (on the second day of anthesis). Two phenological cohorts are furthermore evident at the population level so that individuals bearing predominantly pistillate-phase flowers co-occur with others bearing predominantly staminatephase flowers, thereby promoting xenogamy. The data presented in table 1 show the number of pistillate-phase flowers borne on 10 individuals over $10 \mathrm{~d}$; each of these flowers progresses to form the same number of staminate-phase flowers the following day, enabling inferences to be drawn regarding the number of pistillate-phase flowers that could potentially have been pollinated by staminate flowers borne concurrently on the same plant. Of the total 294 flowers observed (excluding data from the first day, for which data on the number of staminate-phase flowers are not available), only 38 (12.9\%) could potentially have been fertilized by geitonogamy; this is substantially lower than that predicted if equal numbers of pistillate- and staminate-phase flowers had coexisted on each individual.

Geitonogamy is not entirely precluded, however, as occasional disruption of intraindividual flowering synchrony occurs (also observed in Rollinia jimenezii var. nelsonii: Murray and Johnson 1987; table 1). Flower buds in some individuals were occasionally observed to begin anthesis a day earlier than expected (e.g., individual 3, during weeks 8-10; table 1); these flowers therefore coincide with staminate-phase flowers within the same individual, enabling geitonogamy. These rare opportunities for geitonogamy might provide reproductive assurance. Although not evident in the data presented here, it can also be conjectured that occasional disruptions in intraindividual synchrony may enable an individual in one cohort to switch to the other cohort, thereby increasing genetic mixing during reproduction.

It has been suggested that species showing inter- and intraindividual floral synchrony are likely to exhibit stamen abscission immediately after the end of anthesis (Endress 2010), since the retention of such stamens would decrease the efficacy of the synchrony because of the continued availability of older pollen or else would require increased time between floral cohorts. The abscission of stamens in D. chinensis at the start of the staminate phase (ca. 0400 hours) is followed by petal abscission 


\section{Table 3}

Genetic Variability within and among Populations of Desmos chinensis Based on ISSR Data

\begin{tabular}{lccc}
\hline & \multicolumn{3}{c}{ Populations } \\
\cline { 2 - 4 } Genetic parameter & Lung Fu Shan & Pok Fu Lam & Pooled \\
\hline$n$ & 24 & 22 & 46 \\
$P(\%)$ & 78.21 & 88.46 & 91.30 \\
$A \pm \mathrm{SD}$ & $1.78 \pm .42$ & $1.88 \pm .32$ & $1.91 \pm .29$ \\
$A_{\mathrm{e}} \pm \mathrm{SD}$ & $1.48 \pm .40$ & $1.47 \pm .32$ & $1.52 \pm .33$ \\
$H_{\mathrm{o}} \pm \mathrm{SD}$ & $.40 \pm .28$ & $.44 \pm .21$ & $.47 \pm .21$ \\
$b \pm \mathrm{SD}$ & $.27 \pm .20$ & $.29 \pm .16$ & $.31 \pm .16$ \\
$H_{\mathrm{S}} \pm \mathrm{SD}$ & $\ldots$ & $\ldots$ & $.28 \pm .02$ \\
$H_{\mathrm{T}} \pm \mathrm{SD}$ & $\ldots$ & $\ldots$ & $.31 \pm .02$ \\
$D_{\mathrm{ST}}$ & $\ldots$ & $\ldots$ & .028 \\
$G_{\mathrm{ST}}$ & $\ldots$ & $\ldots$ & .090 \\
$N_{\mathrm{m}}$ & $\ldots$ & $\ldots$ & 5.07 \\
\hline
\end{tabular}

Note. $A=$ mean observed number of alleles; $A_{\mathrm{e}}=$ effective number of alleles; $D_{\mathrm{ST}}=$ total genetic diversity distributed among populations; $G_{\mathrm{ST}}=$ coefficient of genetic differentiation between populations; $h=$ gene diversity (Nei 1987); $H_{\mathrm{o}}=$ Shannon's information index; $H_{\mathrm{S}}=$ within-population gene diversity; $H_{\mathrm{T}}=$ total genetic diversity in pooled populations; ISSR = inter-simple sequence repeat; $n=$ sample size; $N_{\mathrm{m}}=$ level of gene flow between populations; $P=$ percentage of polymorphic loci; $\mathrm{SD}=$ standard deviation.

approximately $2 \mathrm{~h}$ later (e in fig. 2), which in turn encourages the departure of the pollinators ( $\mathrm{f}$ in fig. 2). In D. chinensis, stamens therefore abscise from late-anthetic flowers ca. $22 \mathrm{~h}$ before the next cohort of flowers begin anthesis (fig. 2).

Species with inter- and intraindividual floral synchrony are likely to maximize reproductive efficiency by having short anthesis periods, although these are often separated by nonflowering days (Endress 2010). Anthesis in D. chinensis is only $27 \mathrm{~h}$ long, and the rapid termination of staminate function (typically by 0700 hours on day 2; fig. 2) enables the next cohort of flowers to develop the following day, thereby eliminating the need for nonflowering days.

Results from the controlled pollination experiments clearly indicate that $D$. chinensis is self-compatible; although autogamy is precluded by protogyny, comparable levels of fruit-set were obtained in the tests for geitonogamy and xenogamy $(75.0 \%$ and $81.3 \%$, respectively; fig. 4$)$. The high level of fruitset following artificial geitonogamous pollination is not ob- served under natural pollination conditions because of the effects of inter- and intraindividual floral synchrony, and this explains the population genetic structure in which more than $90 \%$ of genetic diversity is distributed within populations rather than between populations.

Pollen flow and seed dispersal are generally believed to be the main factors influencing gene flow (Levin and Kerster 1974; Levin 1981; Loveless and Hamrick 1984). As the two populations of $D$. chinensis included in the ISSR analysis are connected with woodland and shrubland, pollen movement and seed movement between populations is possible. Floral synchrony in D. chinensis increases opportunities for beetle movement between plant individuals and presumably also between populations, as the number of individuals bearing pistillatephase flowers at any one time is presumably half of the entire population. There is no evidence, however, that the members of the two floral cohorts are fixed every flowering season; outcrossing can therefore probably occur between every individual within a population over multiple years.

\section{Conclusions}

As with many members of the early-divergent angiosperm family Annonaceae, Desmos chinensis is pollinated by small nitidulid beetles. The beetles are attracted by sweet floral scents that contain volatile compounds that have previously been demonstrated to be effective beetle attractants.

The flowers are hermaphroditic and protogynous, with anthesis extending over $27 \mathrm{~h}$ and with the pistillate and staminate phases separated by a $6-\mathrm{h}$ nonsexual interim phase. Although controlled pollination experiments show that $D$. chinensis is highly self-compatible, the population genetic study based on ISSR markers reveals that the species predominantly outcrosses under natural conditions; most of the genetic diversity is distributed within populations, suggesting that gene flow between populations is high. The dominance of outcrossing can partly be explained by protogyny, which is an effective mechanism for preventing autogamy. Protogyny cannot prevent geitonogamy, however. We hypothesize that in the absence of a biochemically mediated self-incompatibility mechanism, outcrossing has been promoted by the evolution of inter- and intraindividual floral synchrony, in which pistillate-phase and staminate-phase flowers are rarely borne on the same individual concurrently, thereby precluding transfer of pollen between flowers. This type

Table 4

Comparison of the Mean Genetic Diversity within Populations between Desmos chinensis and Other Annonaceae Species

\begin{tabular}{|c|c|c|c|c|c|c|c|}
\hline Genetic parameter & $\begin{array}{l}\text { Asimina } \\
\text { triloba }\end{array}$ & $\begin{array}{l}\text { Desmos } \\
\text { chinensis }\end{array}$ & $\begin{array}{l}\text { Hubera } \\
\text { korinti }\end{array}$ & $\begin{array}{l}\text { Monoon } \\
\text { coffeoides }\end{array}$ & $\begin{array}{c}\text { Uvaria } \\
\text { semecarpifolia }\end{array}$ & $\begin{array}{l}\text { Long-lived woody } \\
\text { perennial species }\end{array}$ & $\begin{array}{l}\text { Outcrossing animal- } \\
\text { pollinated species }\end{array}$ \\
\hline$P(\%)$ & 64.0 & 88.3 & 49.1 & 68.8 & 66.0 & 49.3 & 47.6 \\
\hline$A$ & 1.64 & 1.830 & 1.491 & 1.688 & 1.487 & 1.76 & 1.72 \\
\hline$A_{\mathrm{e}}$ & $\ldots$ & 1.475 & 1.329 & 1.425 & 1.370 & 1.20 & 1.22 \\
\hline$b^{e}$ & .250 & .280 & .185 & .242 & .216 & .148 & .163 \\
\hline
\end{tabular}

Source. Uvaria semecarpifolia (Attanayake 2010); Monoon coffeoides (Ratnayake et al. 2006, as Polyalthia coffeoides); Hubera korinti (Ratnayake et al. 2006, as Polyalthia korinti); Asimina triloba (Huang et al. 2000); long-lived woody perennial species and outcrossing animalpollinated species (Hamrick et al. 1992).

Note. $\quad P=$ percentage of polymorphic loci; $A=$ mean observed number of alleles; $A_{\mathrm{e}}=$ effective number of alleles; $b=$ gene diversity (Nei 1987). 
of floral synchrony is likely to be very effective at preventing geitonogamy in D. chinensis since fewer than $5 \%$ of pistillatephase flowers are shown to coincide with staminate-phase flowers on the same individual.

Inter- and intraindividual floral synchrony has rarely been reported in the Annonaceae, although we suggest that it may be much more common than this limited number of reports would suggest; most studies of the floral biology of Annonaceae species do not include assessments of sexual functioning of flowers at the population level over several days. The reports that do exist, however, are from species that are phylogenetically very disparate, suggesting that the phenomenon is likely to have evolved independently in multiple different lineages. This provides circumstantial support for the selective advantage of inter- and intraindividual floral synchrony in self-compatible species with protogynous flowers.

\section{Acknowledgments}

We are grateful to Guo Xing for providing her unpublished observations of possible floral synchrony in Friesodielsia, Roger Booth (Natural History Museum, London) for the identification of beetle pollinators, Jessie Lai for assistance with the GCMS analysis, and Laura Wong for general technical assistance.

\section{Literature Cited}

Allen AM, SJ Hiscock 2008 Evolution and phylogeny of selfincompatibility systems in angiosperms. Pages 73-102 in VE FranklinTong, ed. Self-incompatibility in flowering plants: evolution, diversity, and mechanisms. Springer, Berlin.

Attanayake AMAS 2010 Systematics of Uvaria (Annonaceae) in Borneo and the reproductive biology of a Sri Lankan endemic, Uvaria semecarpifolia. PhD diss. The University of Hong Kong.

Azuma H, M Toyota, Y Asakawa 2001 Intraspecific variation of floral scent chemistry in Magnolia kobus DC. (Magnoliaceae). I Plant Res 114:411-422.

Barrett SC, CG Eckert 1990 Variation and evolution of mating systems in seed plants. Pages 229-254 in S Kawano, ed. Biological approaches and evolutionary trends in plants. Academic Press, London.

Bawa KS 1974 Breeding systems of tree species of a lowland tropical community. Evolution 28:85-92.

Bernhardt P, LB Thien 1987 Self-isolation and insect pollination in the primitive angiosperms: new evaluations of older hypotheses. Plant Syst Evol 156:159-176.

Charlesworth D, X Vekemans, V Castric, S Glémin 2005 Plant selfincompatibility systems: a molecular evolutionary perspective. New Phytol 168:61-69.

Culley TM, AD Wolfe 2001 Population genetic structure of the cleistogamous plant species Viola pubescens Aiton (Violaceae), as indicated by allozyme and ISSR molecular markers. Heredity 86:545556.

Dafni A 1992 Pollination ecology: a practical approach. Oxford University Press, Oxford.

Dieringer G, JE Espinosa 1994 Reproductive ecology of Magnolia schiedeana (Magnoliaceae), a threatened cloud forest tree species in Veracruz, Mexico. Bull Torrey Bot Club 121:154-159.

El-Sayed AM 2006 The pherobase: database of insect pheromones and semiochemicals. http://www.pherobase.com.

Endress PK 1984 The flowering process in the Eupomatiaceae (Magnoliales). Bot Jahrb Syst 104:297-319.

2010 The evolution of floral biology in basal angiosperms. Philos Trans R Soc B 365:411-421.

Galen C, RC Plowright 1987 Testing the accuracy of using peroxidase activity to indicate stigma receptivity. Can I Bot 65:107-111.

Ge XJ, M Sun 1999 Reproductive biology and genetic diversity of a cryptoviviparous mangrove Aegiceras corniculatum (Myrsinaceae) using allozyme and intersimple sequence repeat (ISSR) analysis. Mol Ecol 8:2061-2069.

Goodwillie C, S Kalisz, CG Eckert 2005 The evolutionary enigma of mixed mating systems in plants: occurrence, theoretical explanations, and empirical evidence. Annu Rev Ecol Syst 36:47-79.

Hamrick J, MJW Godt, SL Sherman-Broyles 1992 Factors influencing levels of genetic diversity in woody plant species. New For 6: $95-124$
Huang H, DR Layne, TL Kubisiak 2000 RAPD inheritance and diversity in pawpaw (Asimina triloba). J Am Soc Hortic Sci 125:454459.

Igic B, JR Kohn 2006 The distribution of plant mating systems: study bias against obligately outcrossing species. Evolution 60:1098-1103.

Igic B, R Lande, JR Kohn 2008 Loss of self-incompatibility and its evolutionary consequences. Int I Plant Sci 169:93-104.

Jürgens A, AC Webber, G Gottsberger 2000 Floral scent compounds of Amazonian Annonaceae species pollinated by small beetles and thrips. Phytochemistry 55:551-558.

Kovats ES 1965 Gas chromatographic characterization of organic substances in the retention index system. Adv Chromatogr 1:229247.

Levin DA 1981 Dispersal versus gene flow in plants. Ann Mo Bot Gard 68:233-253.

Levin DA, HW Kerster 1974 Gene flow in seed plants. Pages 139220 in T Dobzhansky, MK Hecht, WC Steere, eds. Evolutionary biology. Vol 7. Springer, New York.

Lloyd DG 1992 Self- and cross-fertilization in plants. II. The selection of self-fertilization. Int I Plant Sci 153:370-380.

Lora J, M Herrero, JI Hormaza 2011 Stigmatic receptivity in a dichogamous early-divergent angiosperm species, Annona cherimola (Annonaceae): influence of temperature and humidity. Am I Bot 98: 265-274.

Loveless MD, JL Hamrick 1984 Ecological determinants of genetic structure in plant populations. Annu Rev Ecol Syst 15:65-95.

Mayer C, L Adler, WS Armbruster, A Dafni, C Eardley, SQ Huang, PG Kevan, et al 2011 Pollination ecology in the 21st century: key questions for future research. J Pollinat Ecol 3:8-23.

Murray NA, DM Johnson 1987 Synchronous dichogamy in a Mexican anonillo, Rollinia jimenezii var. nelsonii (Annonaceae). Contrib Univ Mich Herb 16:173-178.

Nei M 1987 Molecular evolutionary genetics. Columbia University Press, New York.

Pang CC, RMK Saunders 2014 The evolution of alternative mechanisms that promote outcrossing in Annonaceae, a self-compatible family of early-divergent angiosperms. Bot I Linn Soc 174:93-109.

Pang CC, T Scharaschkin, YCF Su, RMK Saunders 2013 Functional monoecy due to delayed anther dehiscence: a novel mechanism in Pseuduvaria mulgraveana (Annonaceae). PLoS ONE 8:e59951. doi:10.1371/journal.pone.0059951.

Ratnayake RMCS, IAUN Gunatilleke, DSA Wijesundara, RMK Saunders 2007 Pollination ecology and breeding system of Xylopia championii (Annonaceae): curculionid beetle pollination, promoted by floral scents and elevated floral temperatures. Int I Plant Sci 168: $1255-1268$.

Ratnayake RMCS, YCF Su, IAUN Gunatilleke, DSA Wijesundara, RMK Saunders 2006 Reproductive biology of two sympatric spe- 
cies of Polyalthia (Annonaceae) in Sri Lanka. II. Breeding systems and population genetic structure. Int I Plant Sci 167:495-502.

Rogstad SH 1994 The biosystematics and evolution of the Polyalthia hypoleuca species complex (Annonaceae) of Malesia. III. Floral ontogeny and breeding systems. Am I Bot 81:145-154.

Saunders RMK 2012 The diversity and evolution of pollination systems in Annonaceae. Bot J Linn Soc 169:222-244.

Silberbauer-Gottsberger I, G Gottsberger, AC Webber 2003 Morphological and functional flower characteristics of New and Old World Annonaceae with respect to their mode of pollination. Taxon 52:701-718.

Stephenson AG, SV Good, DW Vogler 2000 Interrelationships among inbreeding depression, plasticity in the self-incompatibility system, and the breeding system of Campanula rapunculoides L. (Campanulaceae). Ann Bot 85A(suppl):211-219.

van Heusden E 1992 Flowers of Annonaceae: morphology, classification, and evolution. Blumea $7($ suppl):1-218.
Webber AC 2002 Floral biology and pollination of some Neotropical Annonaceae. Annonaceae Newsl 13:18-21.

Whitehouse H 1950 Multiple-allelomorph incompatibility of pollen and style in the evolution of the angiosperms. Ann Bot 14:199-216.

Wilson TK 1982 Temporal dioecism in Canella alba, an extreme example. Am J Bot 69(suppl):114.

Wyatt TD 2003 Pheromones and animal behaviour. Cambridge University Press, Cambridge.

Yeh FC, RC Yang, TBJ Boyle, ZH Ye, JX Mao 1997 POPGENE, the user-friendly shareware for population genetic analysis. Molecular Biology and Biotechnology Centre, University of Alberta.

Zapata TR, MTK Arroyo 1978 Plant reproductive ecology of a secondary deciduous tropical forest in Venezuela. Biotropica 10:221230.

Zavada MS, TN Taylor 1986 The role of self-incompatibility and sexual selection in the gymnosperm-angiosperm transition: a hypothesis. Am Nat 128:538-550. 